\title{
Agrobacterium rhizogenes Promotes the Initial Growth of Bare Root Stock
} Almond

\author{
By GARY A. STROBEL ${ }^{1 *}$ AND AVI NACHMIAS ${ }^{2}$ \\ ${ }^{1}$ Department of Plant Pathology, Montana State University, Bozeman, Montana 59717, USA \\ ${ }^{2}$ Agricultural Research Organization, Gilat Regional Experiment Station, Mobile Post Negev, \\ Israel
}

(Received 11 September 1984; revised 6 November 1984)

Bare root stock almond trees treated with Agrobacterium rhizogenes 232 had a larger root number and root mass after $90 \mathrm{~d}$ than those treated with autoclaved or filter-sterilized bacterial suspensions, or with medium alone. Treatment with $A$. rhizogenes 232 also led to significant increases in leaf number, stem diameter and shoot elongation during the first growing season after treatment. The bacterium was recoverable from both the rhizosphere and the bulk soil around the treated roots, but never from uninoculated control roots. Thus, the reaction of almond to $A$. rhizogenes was not a pathological one even though this bacterium is classified as a pathogen.

\section{INTRODUCTION}

Agrobacterium rhizogenes is a soil inhabiting micro-organism that occasionally enters plant roots via wounds or natural openings, and this may result in a proliferation of secondary roots leading to a 'hairy root syndrome' (Riker, 1930; Hildebrand, 1934). This is in contrast to Agrobacterium tumefaciens, which causes gall or tumour formation on its hosts. Although $A$. rhizogenes has a wide host range it seems to be strictly confined to dicotyledonous plants. On carrot root discs inoculated with as few as 100 cells of $A$. rhizogenes, root proliferation originating from the pericycle is noted within 2 weeks (Moore et al., 1979). A large molecular weight plasmid ( $\mathrm{Ri}$ ) is positively correlated with the infectivity of $A$. rhizogenes (Moore et al., 1979; White \& Nester, 1980). The exact mechanism whereby the Ri plasmid causes the development of the rooting response is unknown; however, root induction is likely to be the consequence of stable integration of T-DNA into the plant genome (Chilton, et al., 1982). Subsequently, it is likely that genes in the plant are activated and/or there is expression of functions encoded on the incorporated T-DNA. Although the molecular biological consequences of the association of $A$. rhizogenes with higher plants are becoming better understood the overall pathological/biological effects of $A$. rhizogenes on plants have been considered more of a curiosity than a threat to the agricultural activities of man. It is probably for this reason that relatively little work has been done on $A$. rhizogenes since it was first described over 50 years ago. Although it can cause unsightly roots in some nursery stock, it has never been reported as an important pathogen on fieshy rooted species such as carrot, beet, radish or sweet potato. In fact, Moore et al. (1979) indicated that apple trees possessing a form of non-infectious 'hairy root' seemed to possess better drought tolerance than their control counterparts. Therefore, we asked the question, can $A$. rhizogenes serve a useful purpose in agriculture by virtue of its root initiating activity? Plants that especially require root initiating activity are those that are transplanted as bare root nursery stock. When such nursery stock is planted, the root is nearly functionless in providing water to the plant until it forms secondary roots with an abundance of root hairs. This has several consequences: (1) heavy watering schedules are required until root development can occur; (2) pruning of top parts is required to preclude a heavy demand on water from the root 
system; (3) there is a lack of vigour of the plant in the first few years after transplanting; (4) death of plant parts due to desiccation can occur; and (5) less than adequate stands in the orchard or forest may be produced.

This report presents evidence for some early positive growth responses in the field in bare root nursery stock of almond that was inoculated with $A$. rhizogenes at the time of planting. Data on the survival of $A$. rhizogenes in the rhizosphere and bulk soil of almond roots are also presented. Overall, the results suggest that there may be benefits of inoculating bare root stock plant material with $A$. rhizogenes in order to promote early plant-development, especially under conditions of limited availability of moisture.

\section{METHODS}

Bacterial strains and culturing conditions. The 'super rooting' strain of Agrobacterium rhizogenes used in these studies was selected from a population of $A$. rhizogenes TR105 (L. Moore, Oregon State University, USA). Thousands of individual colonies of $A$. rhizogenes TR 105 were picked from agar plates of yeast extract/mannitol (YM) medium, grown up on liquid YM medium (Abdel-Ghaffar \& Jensen, 1966) and systematically screened for their enhanced ability to produce rooting in the carrot root disc assay (Moore et al., 1979). Any mutants arising would have been the result of a spontaneous genetic event. From over 3000 colonies that were screened, one, designated $A$. rhizogenes 232 , usually produced more roots on carrot and parsnip root discs than the corresponding wild-type $A$. rhizogenes TR 105 . No apparent differences between the fragmentation patterns of the EcoRI digests of the Ri plasmid from strains 232 and TR 105 were noted. We regard strain 232 essentially as a normal strain, apparently differing from TR 105 only in its root inducing ability. A. rhizogenes 232 was used in the plant treatment experiments described in this report.

Agrobacterium radiobacter NT1, lacking the Ri plasmid and originally derived from a Ti cured strain of $A$. tumefaciens, was acquired from L. Moore.

Plants. Almond (Prunus amygdalus) nursery stock material was at least $50 \mathrm{~cm}$ tall (above-ground parts) and the main stem was universally $1.0 \mathrm{~cm}$ in diameter $20 \mathrm{~cm}$ above the crown region (ground level). The root stock was bitter almond cultivar no. 14 (a local Israeli type) and the scion stock was no. 51 (also a local Israeli type).

Short term rooting experiment. To determine the effects of $A$. rhizogenes on almond roots, a short term experiment $(90 \mathrm{~d})$ was conducted. The larger roots of the nursery stock were pruned about $1-2 \mathrm{~cm}$ from their termini in order to expose fresh tissue. Five to eight nursery stock plants were placed for $24 \mathrm{~h}$ in darkness at $20-23^{\circ} \mathrm{C}$ in each of six large containers containing the following solutions or suspensions mixed 1:5 with YM medium: (1) an autoclaved suspension of $A$. rhizogenes 232 , (2) filter sterilized $(0.45 \mu \mathrm{m}$ pore size) YM medium in which $A$. rhizogenes had grown, (3) YM medium alone, (4) YM medium containing $A$. rhizogenes 232 (late exponential culture containing about $10^{9}$ cells $\mathrm{ml}^{-1}$ ), (5) autoclaved suspension of $A$. radiobacter NT1, and (6) YM medium containing $A$. radiobacter NT1 (late exponential culture containing about $10^{9}$ cells $\mathrm{ml}^{-1}$ ).

The biological effects of $A$. rhizogenes 232 on the roots of the nursery stock were examined $90 \mathrm{~d}$ after they were placed as groups in single holes and covered with a sandy loess soil at the Gilat Regional Experiment Station, Israel. The plants were mist sprayed with 25 litres of water over $6 \mathrm{~h}$ every $5 \mathrm{~d}$. The plants were carefully removed from the soil and the roots thoroughly washed with water prior to measurements being taken.

Longer-term field experiment. Sets of almond nursery stock were treated for $24 \mathrm{~h}$ either with late exponential phase cultures of $A$. rhizogenes 232 diluted 1:5 with water or with YM medium (control) diluted 1:5 with water. These plants were also placed in the field at the Gilat Regional Experiment Station in a block design with two blocks of each of the treatment and the control plants. This design was preferred in order to preclude any cross contamination that might result from mixing treatment and control trees in the same block. Each block contained at least 24 trees and planting was done in mid-May. Watering was done every $10 \mathrm{~d}$ by drip irrigation over $4 \mathrm{~h}$ with 20 litres being applied per tree. This rate was increased by approximately $10 \%$ each month due to the increased evaporation rate. A solution of fertilizer $(6 \%$ each of $\mathrm{N}, \mathrm{P}$ and $\mathrm{K}$, plus microelements) was added to the irrigation water at 50-100 p.p.m. During the course of the experiment the day/night temperature ranged from $10{ }^{\circ} \mathrm{C}$ to $36^{\circ} \mathrm{C}$, and there was no measurable precipitation.

Measurements of plants. In the short term rooting experiment, the number of new roots per tree was counted after the roots had been cleaned with water. The new roots, because of their dark colour and small size, were easily distinguished from the older roots. They were counted and then carefully removed from each tree, and were dried and weighed.

In the longer term field experiment designed to determine the effect of $A$. rhizogenes 232 on the above ground growth of almond, measurements were made of the stem diameter $20 \mathrm{~cm}$ above the crown region (ground level) (at the beginning of the experiment all the nursery stock had a stem diameter of $1.0 \mathrm{~cm}$ at this level). The stem diameter of every tree was measured $90 \mathrm{~d}$ after planting, at which time the majority of wood deposition had occurred. Since the number of leaves per tree was very large, a leaf count per tree was made on 12-15 randomly 
selected trees from each block $120 \mathrm{~d}$ after planting, when leaf development was complete. The length of newly developing side branches was also measured on trees selected at random from each block, at $60 \mathrm{~d}$ (mid season) and $150 \mathrm{~d}$ (late season) after planting. Seven to ten of the longest branches on each of the selected trees were measured and the mean values calculated. These values were then used to calculate the overall value for each block.

Isolation of $A$. rhizogenes from soil samples. To determine whether $A$. rhizogenes continued to be associated with plants throughout the growing season soil samples were collected from the rhizosphere (soil clinging to roots) and the bulk soil ( $2-4 \mathrm{~cm}$ from the main root) at $5-10 \mathrm{~cm}$ below ground level of randomly sampled trees in late season (150-180 d after planting). Dried soil samples $(15 \mathrm{mg})$ of each were spread uniformly on agar plates containing a semi-selective medium for agrobacteria. This medium contained mannitol instead of lactose, and $\mathrm{NaNO}_{3}$ instead of $\mathrm{KNO}_{3}$ according to Clark (1969), and cycloheximide and bacitracin at the concentrations given by Schroth $e t$ al. (1965). The plates were incubated at $27^{\circ} \mathrm{C}$. When bacterial colonies developed, at least eight areas of each plate supporting growth were sampled with a loop and each sample was applied to a carrot root disc acording to Moore et al. (1979). For each soil sample tested, production of roots by any of the eight root discs was taken as a positive indication that $A$. rhizogenes was associated with the tree from which the sample had been taken.

\section{RESULTS AND DISCUSSION}

The effect of $A$. rhizogenes 232 on rooting of almond root stock was tested in a short term $(90 \mathrm{~d})$ experiment. It had been shown previously that only $A$. rhizogenes carrying the Ri plasmid could cause root proliferation in dicotyledonous plants (Moore et al., 1979). Also, members of the family Rosaceae have been noted to be especially prone to A. rhizogenes infection (Riker, 1930; Hildebrand, 1934). Thus, at the outset of this work it was important to demonstrate adequately that $A$. rhizogenes 232 would cause significant biological effects in almond. Ninety days after inoculation the mean number of new roots per tree was significantly higher $(P \leqslant 0.007)$, and the total dry weight of new roots was greater, in the plants treated with $A$. rhizogenes 232 as compared with all other treatments (Table 1). This result confirms the earlier work of Moore $e t$ al. (1979), who showed that only living bacteria carrying the Ri plasmid were necessary to promote root initiation in the carrot root assay. Cell free extracts of $A$. rhizogenes 232, cultures of A. radiobacter NT1 (which lacks the Ri plasmid) or killed cells were completely ineffective in the promotion of new root formation. This suggests that any exogenous phytohormones produced by $A$. rhizogenes 232 are by themselves inadequate in promoting root initiation.

Since $A$. rhizogenes 232 was capable of promoting root development in bare root stock almond, we undertook a longer term experiment to determine if $A$. rhizogenes 232 would have any effect in enhancing plant development. The rationale for this approach is that the top growth of nursery stock planted in the form of bare root material usually places more demand on the root

Table 1. Effect of various preparations of $A$. rhizogenes 232 and $A$. radiobacter NTI on root production in bare root stock almond

The plants (Israeli local var. 14 and scion stock no. 51) were treated for $24 \mathrm{~h}$ at $22^{\circ} \mathrm{C}$ with late exponential phase cultures (about $10^{9} \mathrm{cells} \mathrm{ml}^{-1}$ ), autoclaved or filter sterilized cultures, or YM medium alone, which were previously mixed $1: 5$ with YM medium. The plants were then placed in a sandy loess soil. After $90 \mathrm{~d}$ the new roots were counted, harvested and weighed (dry wt). See Methods for additional details. Values are means of 5-8 measurements.

\begin{tabular}{|c|c|c|}
\hline Treatment & $\begin{array}{l}\text { Mean no. } \\
( \pm S D) \text { of new } \\
\text { roots per tree }\end{array}$ & $\begin{array}{c}\text { Mean } \\
\text { dry wt of } \\
\text { new roots per tree }\end{array}$ \\
\hline n & $22 \pm 9$ & 0.87 \\
\hline 232 & $36 \pm 15^{*}$ & 1.51 \\
\hline 232 (autoclaved) & $28 \pm 8$ & 0.97 \\
\hline 232 (filter sterilized) $\ddagger$ & $22 \pm 10$ & 1.01 \\
\hline er NTl & $20 \pm 10$ & 0.78 \\
\hline er NT1 (autoclaved) $\dagger$ & $23 \pm 11$ & 0.68 \\
\hline
\end{tabular}

Medium alone

A. rhizogenes 232

A. rhizogenes 232 (autoclaved) $\dagger$

A. rhizogenes 232 (filter sterilized) $\ddagger$

A. radiobacter NT

A. radiobacter NT1 (autoclaved) $\dagger$
* This mean is different from the mean of all the other means at $P \leqslant 0.007$. $\dagger 20 \mathrm{~min}$ at $120 \mathrm{lbf} \mathrm{in}^{-2}(828 \mathrm{kPa})$.

$\ddagger 0.45 \mu \mathrm{m}$ pore size. 
Table 2. Effect of A. rhizogenes 232 on the growth of almond during the first growing season after transplanting

The root almond stock (Israeli local var. 14 and scion stock no. 51) were treated for $24 \mathrm{~h}$ either with a late exponential phase culture of $A$. rhizogenes 232 diluted $1: 5$ with water or with YM medium (control) diluted $1: 5$ with water. Both the treatment and control trees were each planted in two separate blocks in the sandy soil of the Gilat Desert Experiment Station, Israel. All details of plant growth measurements, irrigation and fertilization are given in Methods. Values are means \pm SD of 10-24 measurements. Values followed by the same letter are not significantly different at $P \leqslant 0.05$.

\begin{tabular}{|c|c|c|c|c|}
\hline & $\begin{array}{c}\text { Total no. } \\
\text { of leaves per } \\
\text { plant at } 120 \mathrm{~d}\end{array}$ & $\begin{array}{c}\text { Stem } \\
\underset{(\mathrm{cm})}{\text { diameter at }} 90 \mathrm{~d}\end{array}$ & $\begin{array}{c}\text { Branch } \\
\text { length at } 90 \mathrm{~d} \\
(\mathrm{~cm})\end{array}$ & $\begin{array}{c}\text { Branch } \\
\text { length at } 150 \mathrm{~d} \\
\text { (cm) }\end{array}$ \\
\hline
\end{tabular}

Medium alone control

(block 1)

A. rhizogenes 232

(block 2)

Medium alone control

(block 3)

A. rhizogenes 232

(block 4)

$\begin{array}{rl}577 \pm 121^{a} & 1 \cdot 40 \pm 0 \cdot 17^{c} \\ 1031 \pm 273^{b} & 1 \cdot 80 \pm 0.21^{d} \\ 734 \pm 111^{a} & 1 \cdot 40 \pm 0.14^{c} \\ 1276 \pm 326^{b} & 1 \cdot 86 \pm 0.28^{d}\end{array}$

$$
\begin{aligned}
& 40 \pm 8^{e} \\
& 62 \pm 7^{f} \\
& 44 \pm 5^{e} \\
& 58 \pm 10^{f}
\end{aligned}
$$$$
59 \pm 11^{g}
$$$$
101 \pm 27^{h}
$$$$
75 \pm 10^{g}
$$$$
120 \pm 15^{h}
$$

system for water than it is capable of supplying. This may occur because the water uptake takes place through root hairs located on secondary roots; bare root stock almond, at the time of planting, generally has no secondary roots with functional root hairs. Top growth could perhaps occur at a rate better and faster than normal if root formation could be enhanced. For this reason, a longer term field experiment was set up in order to ascertain the effects of $A$. rhizogenes 232 on the above ground portions of almond nursery stock during its first season of growth. There were significant differences $(P \leqslant 0.05)$ in stem diameter, number of leaves and mean length of branches between almonds (in both blocks) treated with A. rhizogenes 232 and those treated with medium alone (control) (Table 2, Fig. 1). In fact, the mean stem diameter of almonds treated with $A$. rhizogenes 232 translates into a cross sectional area $(20 \mathrm{~cm}$ above ground) nearly twice that of the control almonds treated with the medium alone. We presume that these differences are due to the increased root mass of the almonds treated with $A$. rhizogenes 232 (Table 1). However, even though genetic transformation of the root tissue occurs, we cannot rule out other explanations for the enhanced growth effects (Chilton et al., 1982), such as changes in phytohormone quantity and quality. It is conceivable that phytohormones produced by $A$. rhizogenes in the rhizosphere and bulk soil contribute to some of the growth effects observed in the almond trees. This point is supported by the aberrant growth that occurred in soybean seedlings arising from seeds which were treated with large numbers of $A$. rhizogenes (Jaynes \& Strobel, 1981). Such growth effects apparently occur via phytohormones produced by $A$. rhizogenes and not by genetic transformation per se.

The positive effects of $A$. rhizogenes 232 on the initial growth of bare root stock plants is not confined to almond. Similar experiments have been done in Israel on bare root stock olive with results comparable to those shown in Table 2.

At the end of the growing season we sampled rhizosphere soil (clinging to the root) and bulk soil ( $2-4 \mathrm{~cm}$ from the root) on at least 10 almonds in both treated and control groups to determine if $A$. rhizogenes continued to be associated with the plants. In the case of nursery stock treated with $A$. rhizogenes 232 we were able to recover $A$. rhizogenes from $50 \%$ of the rhizosphere soil samples and from $75 \%$ of the bulk soil samples. We could not detect $A$. rhizogenes in any of the soil samples from the control trees treated with medium alone. We suggest that the $A$. rhizogenes that was recovered was the same organism that was originally applied, since no root inducing organisms were found in the soil samples from the control trees. The organism had survived in the rhizosphere and bulk soil regions for at least one growing season.

There may be additional short term effects of $A$. rhizogenes on bare root stock plants including better establishment and earlier yields of fruit. We anticipate that drought tolerance might be 

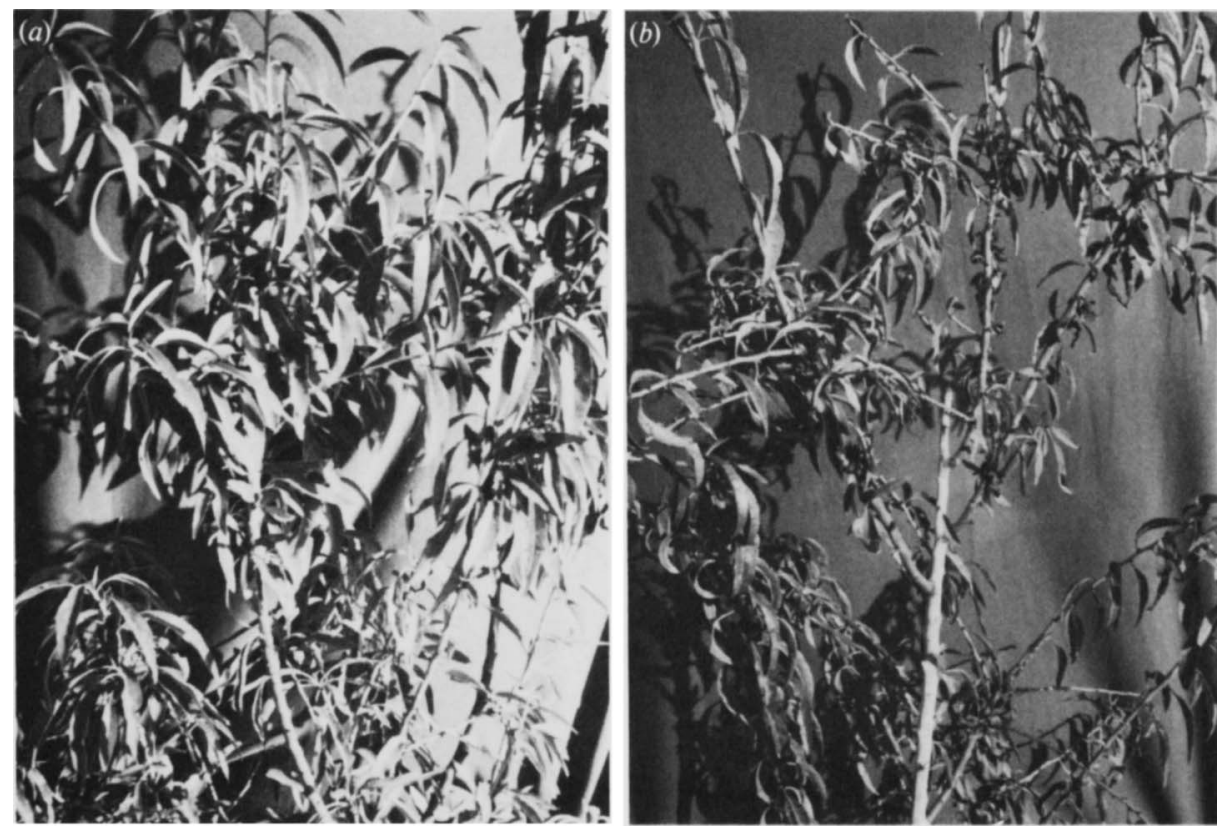

Fig. 1. Stem and foliage of almonds $150 \mathrm{~d}$ after being treated with $(a)$ A. rhizogenes 232 or $(b)$ medium alone (control).

one of the long term benefits of genetic transformation with $A$. rhizogenes (Moore et al., 1979; Strobel \& Mathre, 1982). Until such determinations are made we cannot anticipate the long term effects on yield, growth or the relationship of the transformed plant to other organisms, including infections caused by root infesting nematodes and disease causing fungi and bacteria. Overall, there seems to be reason to be cautiously optimistic that $A$. rhizogenes has some potential to be a useful organism in agriculture, horticulture and forestry.

This work was supported in part by a grant from Phytogen and the Montana Agricultural Experiment Station.

\section{REFERENCES}

Abdel-Ghaffar, A. S. \& Jensen, H. L. (1966). The rhizobia of Lupinus densiflorus Benth., with some remarks on the classification of root nodule bacteria. Archives of Microbiology 54, 343-405.

Chilton, M. D., Tepfer, D. A., Petit, A., David, C., Casse-Delbart, F. \& Tempe, J. (1982). Agrobacterium rhizogenes insert T-DNA into the genomes of the host plant root cells. Nature, London 295, 432-434.

Clark, A. G. (1969). A selective medium for the isolation of Agrobacterium species. Journal of Applied Bacteriology 32, 348-351.

Hildebrand, E. M. (1934). Life history of the hairyroot organism in relation to its pathogenesis on nursery apple trees. Journal of Agricultural Research 48, 857-885.

JAYNES, J. M. \& Strobel, G. A. (1981). The position of Agrobacterium rhizogenes. International Review of Cytology (suppl.) 13, 105-125.
Moore, L. W., Warren, G. \& Strobel, G. A. (1979). Involvement of a plasmid in the hairy root disease of plants caused by Agrobacterium rhizogenes. Plasmid 2, 617-626.

RIKER, A. J. (1930). Studies on infectious hairy root of nursery apple trees. Journal of Agricultural Research 41, 507-540.

Schroth, M. N., Thompson, J. P. \& Hildebrand, D. C. (1965). Isolation of Agrobacterium tumefaciensA. radiobacter group from soil. Phytopathology 55, 645-647.

Strobel, G. A. \& Mathre, D. E. (1982). Plant Disease. In Outlook for Science and Technology, pp. 232-252. San Francisco: National Research Council-NAS, W. H. Freeman \& Co.

White, F. F. \& Nester, E. W. (1980). Hairy root plasmid encodes virulence traits in Agrobacterium rhizogenes. Journal of Bacteriology 141, 1134-1141. 